\title{
"EU ESTUDO PORQUE É UMA COISA QUE ME DÁ PRAZER, SATISFAÇÃO, GOSTO": a escola em narrativas de professores de Araguaína-TO'
}

\author{
Bruna da Silva Cardoso2 \\ Rosária Helena Ruiz Nakashima³
}

\section{RESUMO}

Este artigo tem como objetivo analisar as histórias de vida de quatro professores/as para compreender as lógicas de relação com o saber e a escola, bem como seus desdobramentos na construção do ser professor/a. A História oral foi o caminho teórico-metodológico que fundamentou a investigação das narrativas de escolarização de professores da rede estadual de ensino da cidade de AraguaínaTO. Nesta pesquisa, evidenciou-se a importância da escola como espaço-lugar de formação na construção do ser professor/a e a relação com a família e com professores/as foram narradas, pelos/as entrevistados/as, como momentos formadores e marcantes.

Palavras-chave: História oral. Narrativas. Relação com o saber.

\section{"I STUDY BECAUSE IT IS SOMETHING THAT GIVES ME PLEASURE, SATISFACTION, LIKING": School in narratives of teachers of Araguaína-TO}

\begin{abstract}
This article analyzes the life stories of four teachers from the state school system in the city of Araguaína-TO to understand the logic of their relationship with knowledge and the school environment, as well as how the interplay of these relationships influences their becoming teachers. Oral history was the theoretical-methodological path that supported the investigation of their schooling narratives. The results of the

\footnotetext{
1 Este artigo faz parte da pesquisa que resultou em uma dissertação de mestrado, defendida em 2017.

2 Graduada em História (Licenciatura) e Mestra em Estudos de Cultura e Território pela Universidade Federal do Tocantins (UFT). Professora da Rede Estadual de Ensino do Tocantins, no Colégio Estadual Sebastião Rodrigues Sales, Brasilândia-TO. Orcid iD: https://orcid.org/0000-0002-3705-3507.E-mail: nhabrunisc@gmail.com

3 Pedagoga. Mestra em Educação pela Unicamp. Doutora na área de Didática, Teorias de Ensino e Práticas Escolares pela Faculdade de Educação da USP. Professora Adjunta do Curso de Licenciatura em História e Docente do Programa de Pós-Graduação em Estudos de Cultura e Território (PPGCult), da Universidade Federal do Tocantins (UFT), Campus de Araguaína-TO. Orcid iD: https://orcid.org/0000-0001-7798-6363. E-mail: rosaria@uft.edu.br
} 
research reveal the importance of school as an educative space-place in the construction of becoming a teacher. They also suggest that the relationship with family members and with other teachers constitute educative and remarkable moments.

Keywords: Oral history. Narratives. Relationship to knowledge.

\section{"ESTUDIO PORQUE ES UNA COSA QUE ME DA PLACER, SATISFACCIÓN, ME GUSTA": Ia escuela en las narrativas de los maestros de Araguaína-TO}

\section{RESUMEN}

Este artículo tiene como objetivo analizar las historias de vida de cuatro docentes con el propósito de comprender la lógica de la relación entre elconocimiento y la escuela, así como explicar sus consecuencias en la construcción del ser docente en en Araguaína, Brasil en 2017.Se utilizó la historia oral como eje de la construcción teórica-metodológica que sustenta la investigación sobre las narrativas escolares de los docentes en el sistema escolar estatal de la ciudad de Araguaína-TO. Los hallazgos obtenidos permiten discutir la importancia de la escuela como espacio medular en que se produce el conocimiento y la formación no sólo sobre la del ser docente, sino también con los ámbitos la familiares, así como se explica la lógica de la relación entre los docentes entrevistados y la práctica desarrollada en su contexto socioeducativo y con los docentes fue narrada, por los entrevistados, como momentos formadores y notables.

Palabras clave: Historia oral. Narrativas. Relación con el saber.

\section{INTRODUÇÃO}

Esta pesquisa buscou compreender como as relações com o saber e a escola se desdobram e se articulam na construção do ser professor/a. Para conhecer quem é o sujeito que ensina e aprende na educação básica foi necessário compreender quem são esses professores; o que pensam sobre a educação; como lidam com as dificuldades da profissão; como percebem a escola; quais suas expectativas em relação à docência etc. Assim, este artigo analisou as histórias de vida de professores/as, para compreenderem as lógicas de relação com o saber, que se desdobraram em dinâmicas com a família, a escola e a profissão.

Foram entrevistados quatro professores, em atuação no Ensino Fundamental e Médio, da rede estadual de ensino de Araguaína-TO. Dois com formação em Letras, um formado em História e uma formada em Geografia, com o mínimo de cinco anos de atuação e que tivessem 
concluído o ensino superior a partir de 1996, ano de promulgação da atual Lei de Diretrizes e Bases (LDB) n 9.394/96, considerando sua importância para a educação brasileira e para a formação de professores.

Este artigo foi estruturado a partir de alguns apontamentos oriundos das contribuições das histórias orais de vida, para a realização de pesquisas sobre a docência, em seguida, foram evidenciadas as lógicas da relação com o saber e a escola desses/as entrevistados/as, fundamentadas, principalmente, nas contribuições de Bernard Charlot (1996; 2000; 2002; 2005; 2011).

Assim, como ponto de partida para a elaboração das reflexões subsequentes, consideramos que as trajetórias dos/as professores/as da educação básica precisam ser valorizadas pela comunidade acadêmica e pela sociedade em geral.

\title{
HISTÓRIAS ORAIS DE VIDA E REFLEXÕES SOBRE A DOCÊNCIA
}

Para Paul Thompson (1992, p. 44), "a história oral é uma história construída em torno de pessoas", na mesma direção, Portelli (2016) enfatiza que a história oral é uma "arte da escuta". Desse modo, a história oral nos possibilitou a escuta das histórias de vida dos professores, com o intuito de mostrar como elas enriquecem as pesquisas sobre a docência e têm muito a nos ensinar.

A História oral não é composta apenas por um procedimento e não é apenas a entrevista que a constitui. Pois, a

\begin{abstract}
História Oral é um conjunto de procedimentos que se inicia com a elaboração de um projeto e que continua com o estabelecimento de um grupo de pessoas a serem entrevistadas. O projeto prevê: planejamento da condução das gravações com definição de locais, tempo de duração e demais fatores ambientais; transcrição e estabelecimento de textos; conferência do produto escrito; autorização para uso; arquivamento e, sempre que possível, a publicação dos resultados que devem, em primeiro lugar, voltar ao grupo que gerou as entrevistas (MEIHY; HOLANDA, 2013, p. 15).
\end{abstract}

Nesta pesquisa, reconhecemos os entrevistados como nossos interlocutores para construir uma relação de reciprocidade (PORTELLI, 2016) 
e confirmamos que ao relatarem suas experiências, os professores transformaram $\mathrm{O}$ que vivenciaram em linguagem, selecionaram e organizaram suas vivências, de acordo com determinados sentidos (ALBERTI, 2006). Portelli (2016, p. 10) mostra que as fontes orais não são encontradas, mas "cocriadas" pelo historiador.

[...] Elas não existiriam sob a forma que existem sem a presença, o estímulo e o papel ativo do historiador na entrevista feita em campo. Fontes orais são geradas em uma troca dialógica, a entrevista: literalmente uma troca de olhares. Nessa troca, perguntas e respostas não vão necessariamente em uma única direção. A agenda do historiador deve corresponder a agenda do narrador; mas o que o historiador quer saber pode não necessariamente coincidir com o que o narrador quer contar. Como consequência, toda a agenda da pesquisa pode ser radicalmente revista.

Thompson (1992) também destaca que uma das principais vantagens da História oral é o trabalho de campo; assim como proporciona que os narradores olhem para trás e enxerguem a própria vida, a partir dos diálogos estabelecidos entre entrevistador e entrevistado. Este autor compreende que a História oral,

[...] é uma abordagem ampla, é a interpretação da história e das sociedades e culturas em processo de transformação, por intermédio da escuta às pessoas e do registro das histórias de suas vidas. A habilidade fundamental na história oral é aprender a escutar. Gostaria de enfatizar que considero a história oral como um campo interdisciplinar. Ela não é simplesmente histórica, mas também sociológica - eu mesmo trabalho num departamento de sociologia, na Universidade de Essex -, antropológica e é parte dos estudos culturais em geral, pois ela se baseia nessa forma fundamental de interação humana, que transcende as disciplinas (THOMPSON, 2006, p. 20).

A história oral de vida, como afirma Alberti (2006), volta-se para a trajetória do entrevistado, ou seja, tem como preocupação central o indivíduo na história, como ele constrói e significa as suas experiências. Assim, as histórias de vida,

[...] têm como centro de interesse o próprio indivíduo na história, incluindo sua trajetória desde a infância até o momento em que fala, passando pelos diversos acontecimentos e conjunturas que presenciou, vivenciou ou de que se inteirou. Pode-se dizer que a entrevista de história de vida contém, em seu interior, diversas entrevistas temáticas, já que, ao longo da narrativa da trajetória de 
vida, os temas relevantes para a pesquisa são aprofundados (ALBERTI, 2006, p. 175).

Trabalhar com histórias de vida de professores/as nos instigou a pensar sobre muitas questões que envolvem a formação docente, especialmente sobre a relação que esses sujeitos estabelecem(ram) com o saber e a escola. O fazer História oral envolve, para além de procedimentos técnicos, a abertura para aprender com as entrevistas. Pressupõe compreender que lançar mão dessa metodologia é se deparar constantemente com desafios e situações inesperadas. Pois,

[...] O que o entrevistado fala também depende da circunstância da entrevista e do modo pelo qual ele percebe seu interlocutor. Quando é solicitado ao falar sobre o passado diante de um gravador ou uma câmera, cria-se uma situação artificial, pois a narrativa oral, ao contrário do texto escrito, não costuma ser feita para registro. É claro que o entrevistado acostumado a falar em público e a conceder entrevistas, para o rádio ou a televisão terá um desempenho diferente daquele que não tem essa experiência. Para alguns, o fato de estar concedendo uma entrevista pode ser motivo de orgulho, porque sua experiência foi considerada importante para ser registrada. Para outros, a situação pode ser inibidora. Além disso, como a linguagem oral é diferente da escrita, leitores desavisados podem estranhar o texto da entrevista transcrita, geralmente menos formal do que um texto produzido na forma escrita. Todos esses fatores devem ser levados em conta quando da produção e da análise da fonte oral (ALBERTI, 2006, p. 171).

Segundo Alberti (2006, p. 165), a História oral nos permite estudar as "formas como pessoas ou grupos efetuaram e elaboraram experiências, incluindo situações de aprendizado e decisões estratégicas", o pesquisador pode ter acesso a "histórias dentro da história" (p. 166), já que,

[...] Uma das principais vantagens da História oral deriva justamente do fascínio da experiência vivida pelo entrevistado, que torna o passado mais concreto e faz da entrevista um veículo bastante atraente de divulgações de informações sobre o que aconteceu. Esse mérito reforça a responsabilidade e o rigor de quem colhe, interpreta e divulga entrevistas, pois é preciso ter claro que a entrevista não é um 'retrato' do passado (ALBERTI, 2006, p. 170).

As entrevistas de histórias de vida foram compreendidas também como um espaço de rompimento dos lugares de quem pesquisa e de quem 
é pesquisado, em que todos foram sujeitos do processo. Estas envolvem um trabalho de pavimentação do passado e possibilita a construção de inúmeros sentidos do presente e do futuro; recolhem memórias, experiências, percursos e subjetividades; devem abranger toda a vida do sujeito, desde a infância até a atualidade (JOSSO, 2004).

Bragança (2012a) traz o trabalho com as histórias de vida a partir de uma perspectiva interdisciplinar, o que pressupõe diferentes aportes teóricos e diversas possibilidades de interpretação. Assim, esta pesquisa compreende o trabalho com as histórias de vida dos professores como um processo de formação e de construção de saberes partilhados, isto é, que proporcionam a produção de conhecimentos e a realização de pesquisas fora do quadro lógico-formal e positivista, distanciando-se da compreensão da docência como uma atividade mecânica (BRAGANÇA, 2012a).

Assumir essa postura de pesquisa pressupõe compreender que 0 diálogo com as histórias de vida não pretende

[...] apenas encontro de pistas e indicativos sobre a natureza do processo formador ao longo da vida, mas a possibilidade de perceber em que medida a vivência da experiência narrativa, por meio da dinâmica proposta, poderia favorecer, ela própria, um caminho instituinte de formação para todos os envolvidos, incluindo professoras e investigadoras (BRAGANÇA, 2012b, p. 586).

Durante o processo de seleção dos/as entrevistados/as enfrentamos alguns percalços. Em primeiro momento, visitamos três escolas e, ao apresentarmos a proposta de pesquisa, recebíamos a informação de que o corpo docente não tinha tempo para participar, devido as diversas atribuições escolares. Outros fatores também foram apontados para a não participação, a saber: o período conturbado que os/as professores/as do estado do Tocantins estão passando nos últimos anos, por períodos de greves e reivindicações da categoria; professores/as se aposentando e também professores/as que se recusaram a dialogar conosco.

Assim, os/as professores/as escolhidos/as foram contactados através de redes de conhecidos, que faziam a indicação e após uma conversa inicial tínhamos ou não uma resposta positiva de aceitação de participação. 
Também, nesse segundo momento de seleção dos entrevistados, recebemos muitas respostas negativas e houve certa resistência por parte de alguns professores em ceder suas histórias para serem gravadas. Como tínhamos um prazo a cumprir, fechamos em quatro professores e realizamos as entrevistas. Como a proposta do mestrado era interdisciplinar, optamos por entrevistar docentes de diferentes áreas de formação, como Letras, História e Geografia, áreas que eram objetos de discussão teórica e metodológica no mestrado em curso naquele momento.

Os/as interlocutores/as desta pesquisa são professores/as em atuação, na rede estadual de ensino da cidade de Araguaína-TO. Os critérios estabelecidos para selecioná-los/as foram: ter no mínimo cinco anos de atuação na profissão; ter formação superior antes de iniciar o exercício na docência; ter cursado o ensino superior após o ano de 1996, ano de promulgação da LDB; ser professor/a da educação básica e; aceitar participar da pesquisa, incluindo a gravação das entrevistas em áudio, a transposição para texto escrito e seus usos em produções textuais.

Tivemos no mínimo dois encontros com cada docente entrevistado/a, um para conversar sobre a proposta e outro para fazer a entrevista. Além disso, também tiveram conversas por ligação telefônica; mensagem de celular; e e-mail, para tirar dúvidas, marcar os encontros e para ter a aprovação dos professores em relação ao material transcrito, assim como em relação ao trabalho final da pesquisa.

Os locais em que as entrevistas foram realizadas foram escolhidos pelos/as professores/as. Três entrevistas foram realizadas em um prédio da Universidade Federal do Tocantins, por ser um lugar mais silencioso e por ser de fácil acesso tanto para a entrevistadora como para os/as entrevistados/as. Uma entrevista foi realizada na casa de uma das professoras, por opção dela. No geral, os áudios das gravações ficaram inteligíveis para o procedimento de transcrição.

As entrevistas foram realizadas durante $\mathrm{o}$ ano de 2016, com durações variadas. Com a professora Oliveira: formação em Geografia, a entrevista teve duração de 04 horas e 52 minutos. Com a professora Araujo: formação 
em Letras, duração da entrevista de 02 horas. Com o professor Souza: formação também em Letras, duração da entrevista de 02 horas e 24 minutos. E com o professor Barbosa: formação em História, duração da entrevista de 04 horas e 02 minutos. Foi a partir da transcrição das entrevistas de histórias de vida que obtivemos o material para trabalho e análise nesta pesquisa, sistematizados na sequência.

Por isso, as trajetórias de quatro professores/as ${ }^{4}$ (Quadro 1) foram consideradas fontes de compreensão dos processos históricos e sociais. No Quadro 1, observamos que apenas a professora Araujo é natural da cidade de Araguaína. Desse modo, podemos entender que os demais professores se deslocaram para a cidade buscando oportunidades para estudar, como a professora Oliveira e para trabalhar como os professores Souza e Barbosa. Cabe acrescentar que os quatro professores são concursados do quadro efetivo do Estado do Tocantins.

\section{Quadro 1: Perfil dos/as entrevistados/as}

\begin{tabular}{|l|l|l|l|l|l|l|l|}
\hline Nome & $\begin{array}{l}\text { Ano } \\
\text { de } \\
\text { nasci- } \\
\text { mento }\end{array}$ & $\begin{array}{l}\text { Ida- } \\
\text { de }\end{array}$ & $\begin{array}{l}\text { Naturalida } \\
\text {-de }\end{array}$ & $\begin{array}{l}\text { Área de } \\
\text { formação }\end{array}$ & $\begin{array}{l}\text { Lugar de } \\
\text { formação- } \\
\text { graduação }\end{array}$ & $\begin{array}{l}\text { Ano de } \\
\text { conclu- } \\
\text { são do } \\
\text { ensino } \\
\text { superior }\end{array}$ & $\begin{array}{l}\text { Tempo } \\
\text { docência }\end{array}$ \\
\hline Oliveira & 1975 & $\begin{array}{l}41 \\
\text { anos }\end{array}$ & $\begin{array}{l}\text { Xambioá- } \\
\text { TO }\end{array}$ & Geografia & UNITINS & 1999 & 18 anos \\
\hline Araujo & 1980 & $\begin{array}{l}37 \\
\text { anos }\end{array}$ & $\begin{array}{l}\text { Araguaína } \\
- \text {-TO }\end{array}$ & Letras & UNITINS/UFT & 2000 & 17 anos \\
\hline Souza & 1982 & $\begin{array}{l}35 \\
\text { anos }\end{array}$ & $\begin{array}{l}\text { Marabá- } \\
\text { PA }\end{array}$ & Letras & UFPA & 2010 & 8 anos \\
\hline Barbosa & 1966 & $\begin{array}{l}50 \\
\text { anos }\end{array}$ & $\begin{array}{l}\text { Itabaiana- } \\
\text { PB }\end{array}$ & História & UFPB & 1999 & 18 anos \\
\hline
\end{tabular}

Fonte: Dados da pesquisa (2017).

Para chegar ao ensino superior e depois ao trabalho como professores, esses sujeitos oriundos da região Norte e Nordeste do país, construíram suas trajetórias de formação, conforme análises empreendidas nos tópicos seguintes. A partir das leituras que fizemos das transcrições, dividimos essas reflexões sobre as narrativas dos professores em duas seções: relações com a

4 Os entrevistados assinaram o termo de concessão de direitos, autorizando o uso do conteúdo total e/ou parcial das entrevistas, desde que seus nomes sejam sempre citados. 
família, com a escola e com o saber/aprender; e tipos de relação com o saber e com a escola, destacando a importância dos estudos desenvolvidos na escola.

\section{RELAÇÕES COM A FAMÍLIA, COM A ESCOLA E COM O SABER/APRENDER}

Bernard Charlot (2000) discute e problematiza, sobretudo, a relação de crianças e jovens com o saber e com a escola. Conforme já destacamos, este artigo se propõe a compreender como essas relações se dão em narrativas de professores, que já foram estudantes da educação básica, ao passarem por um histórico de escolarização, e obterem relações com o saber que influenciam na forma como atuam como professores nos dias de hoje. Estes, como professores, continuam aprendendo e estabelecendo relações com o saber e com a escola. Para melhor organização e compreensão dessas relações, foram elaborados os Quadros 2 e 3.

\section{Quadro 2: Relações com a família}

\begin{tabular}{|l|l|}
\hline Professor/a & Narrativas \\
\hline Araujo & $\begin{array}{l}\text { "A minha família sempre priorizou o estudo. Então nós sempre tivemos como } \\
\text { prioridade [...] Não podia faltar isso, não podia faltar escola. E estudar é } \\
\text { importante para a minha família até hoje, é dali que se vence muitas } \\
\text { barreiras [...]". }\end{array}$ \\
\hline Barbosa & $\begin{array}{l}\text { "Meus avós eram, por parte da minha mãe eram da roça, a parte de pai } \\
\text { meu avô era artesão, trabalhava com redes, eu ainda lembro disso assim } \\
\text { [...] mais uma família humilde que teve que batalhar muito, correr muito } \\
\text { atrás. Trabalhar, estudar. Assim, eu sempre gostei de estudar, desde } \\
\text { pequeno, esse meu tio me ajudou muito porque ele sabia que, ele via assim } \\
\text { a possibilidade de estudar [...]". }\end{array}$ \\
\hline Oliveira & $\begin{array}{l}\text { "Meu pai gostava muito de conversar com a gente [...] na boca da noite } \\
\text { quando ele chegava da roça ele costumava tomar o cafezinho e } \\
\text { conversar, senão muitas vezes tomar a tabuada ou pedir a leitura [...]". } \\
\text { "[...]Âs vezes meu pai vinha e buscava o boletim, ele ficava muito feliz, ele } \\
\text { sempre brilhava o rosto e isso é interessante, não é? As fisionomias, era } \\
\text { engraçado isso [...]". } \\
\text { "[...] eu aprendi com ele o nome das árvores, as favas que ele fala, as } \\
\text { sementes, a raiz, a casca de pau serve para isso, para aquilo [...] Meu pai } \\
{[\ldots . .] \text { Então assim, eu sempre tive uma relação muito amistosa com o meu }} \\
\text { pai". } \\
\text { "[...] da minha casa quem primeiro aprendeu a ler e escrever fui eu". }\end{array}$ \\
\hline
\end{tabular}


Souzd

"Meus pais eles sempre incentivaram muito, mesmo assim, eles não tendo muita escolaridade. A minha mãe fez até a oitava série, meu pai até o primeiro ano do ensino médio [...] tudo aquilo que eles sabiam, até onde eles sabiam eles ensinavam para a gente, eles sempre tiveram isso. Meu pai sempre colocou de que não poderia me dar outra coisa, mas ele faria de tudo para que eu estudasse".

"[...] a minha tia sempre trazia as tarefinhas da escola para mim [...]".

Fonte: Dados da pesquisa (2017).

Oliveira encontrava na família, principalmente na figura do pai o incentivo para frequentar a escola. Em sua narrativa, Oliveira falou da saída da casa dos pais para trabalhar como babá, destacando que foi um momento marcante na sua história de vida e narrar sobre esse momento a emocionou. Nos anos oitenta, a professora Oliveira teve que sair da casa dos pais para trabalhar como babá, na casa de outras pessoas, com a justificativa de que seria melhor, pois iria estudar. Para ela, a única saída era estudar, ir à escola e se dedicar aos estudos; mesmo sem tempo e com todas as dificuldades, ela alimentava a esperança de se ter uma vida melhor. Nessa época, não imaginava que um dia faria um curso superior e se tornaria professora concursada.

Segundo Oliveira, a partir da saída da casa dos pais, aos nove anos, passou por muitas dificuldades, mas também teve muitas oportunidades. Nesse contexto, ela não entendia muito bem que a educação era um "caminho de libertação", mas em alguns momentos refletia sobre isso, quando, por exemplo, o pai pegava o seu boletim, conforme podemos visualizar no Quadro 2.

Charlot (2000) entende que o saber é diferente da informação e do conhecimento, pois a informação é algo exterior ao sujeito; o conhecimento resultado da experiência de cada um, a partir de atividades afetivocognitivas, é intransferível; e o saber é algo que o sujeito se apropria na relação com outros sujeitos e com o mundo. Como, nas relações dos professores com os seus familiares. Portanto,

[...] A relação com o saber é, a relação com o mundo, com o outro, e com ele mesmo, de um sujeito confrontado com a necessidade de aprender; A relação com o saber é o conjunto (organizado) das

Revista Exitus, Santarém/PA, Vol. 10, p. 01-28, e020101, 2020. 
relações que um sujeito mantém com tudo quanto estiver relacionado com o 'aprender' e o 'saber'; Ou sob uma forma 'mais intuitiva': a relação com o saber é o conjunto das relações que um sujeito mantém com um objeto, um 'conteúdo de pensamento', uma atividade, uma relação interpessoal, um lugar, uma pessoa, uma situação, uma ocasião, uma obrigação etc. ligados com o aprender e o saber; e por isso mesmo, é também relação com a linguagem, relação com o tempo, relação consigo mesmo enquanto mais ou menos capaz de aprender tal coisa, em tal situação (CHARLOT, 2000, p. 80-81).

A professora Oliveira demonstrou estar em constante aprendizado, porque desde o seu nascimento está submetida a "obrigação de aprender" (CHARLOT, 2000, p. 53). No processo de aprendizagem ou de apropriação do mundo, ela se construiu na relação com outras pessoas, através da educação, iniciando-se, como podemos ver, na relação com a família.

Para Araujo, a escola foi presente desde os primeiros anos de vida, já que sua mãe trabalhava como merendeira na escola em frente à sua casa. A Escola Municipal Gentil Ferreira Brito, lugar do qual a professora tanto se recorda, foi onde ela estudou os primeiros anos do ensino fundamental.

O professor Souza evidenciou que a sua relação com a escola se apresentou como um caminho para um futuro melhor, proporcionando-lhe uma realidade diferente da vivida por seus pais. Ele criou uma forte relação com a escola, sobretudo, por causa do incentivo dos pais e das condições socioeconômicas da família. A escolarização se mostrou como um caminho a ser trilhado na busca de um futuro vislumbrado, isto é, o desejo de conquistar uma vida diferente da vivenciada pelos pais. Desse modo, a escola na história de vida de Souza pode ser vista em termos de futuro.

Percebemos que para o professor Barbosa a escola também representava a possibilidade de transformação da realidade que vivia. A educação escolar proporcionaria o acesso a oportunidades além das que tinha na infância e adolescência. A vida do professor Barbosa é permeada por situações de militância, principalmente na universidade e depois como professor em atuação na educação básica.

O professor Barbosa pouco se recorda sobre a infância e os primeiros anos na escola. Chegou a ser reprovado pelo ensino ser muito rígido, e que 
estudou com a professora Salomé, que ensinava na casa dela. Era a mais procurada, porque ter aulas com ela era uma garantia de que os alunos passariam no exame de admissão para dar continuidade a escolarização e cursar a quinta série ginasial, pois "todo aluno que terminava a quarta série tinha que fazer o exame de admissão". A figura do tio, o único com formação superior da família, professor com formação em História e Geografia e recém-formado em Direito, era o maior incentivador para que Barbosa continuasse sua escolarização, o tio era "um cara bem bacana, que me ajudou muito".

A trajetória de escolarização da professora Araujo mostrou que o caminho dos estudos foi visto como possibilidade de um futuro melhor. Nas narrativas de Oliveira, a continuidade também foi presente. A cada etapa concluída (como relatou quando o pai pegava o seu boletim e ficava feliz ao ver que a filha havia conseguido avançar mais uma etapa), via a escola como uma saída. Assim, a escola era vista em termos de futuro (CHARLOT, 2002).

Barbosa, assim como Oliveira, foi um aluno trabalhador. Trabalhar e estudar, ao mesmo tempo, pode ter sido um dos fatores que mobilizou os professores a continuarem na vida escolar. No caso de Oliveira, por exemplo, os estudos contribuíram para que saísse da casa em que trabalhava, como empregada doméstica, para começar a construir sua vida longe dos desmandos da patroa que não queria que ela estudasse, "isso me deu uma libertação, fui ter minha própria vida" (professora Oliveira).

Para os/as entrevistados/as, o sentido de ir à escola quando crianças se insere no âmbito da valorização e da escola como o lugar de transição para um futuro melhor, para melhorar as condições de vida em relação aos pais, à geração anterior da família. As famílias de Oliveira e Araujo e de Barbosa e Sousa não tiveram acesso à escolarização e enxergam(vam) na escola um espaço de transformação, de libertação, um lugar que pode oferecer caminhos, oportunidades aos filhos que os pais não tiveram. Segundo Charlot (2002, p. 27), os pais "[...] dão grande importância à escola 
porque sabem que não tem outro jeito para os filhos saírem das dificuldades da vida".

Charlot (1996, p. 56 e 57) enfatiza que "a demanda familiar funciona então como motivo principal da mobilização e assegura a continuidade no tempo, às vezes apesar das vicissitudes da história escolar"; "a demanda familiar se torna vontade pessoal de sucesso, mobilização em relação a escola". É preciso ressaltar que o sucesso escolar não depende apenas da demanda familiar, mas da relação de cada sujeito com o saber e com a escola.

Assim, podemos afirmar que o incentivo familiar foi importante para a continuidade da escolarização dos/as entrevistados/as, mas não foi determinante. As famílias dos professores entrevistados não tinham um projeto de escolarização para os filhos que garantisse a certeza de continuidade na escola, mas, percebemos que existia um sonho, de que a cada etapa escolar, os/as filhos/as poderiam ter sucesso por meio da escola.

Charlot (2000) contribui para essa discussão quando nos diz que a origem social dos estudantes não determina o seu sucesso ou fracasso na escola. É preciso nos preocuparmos com as práticas educativas familiares e não apenas com as posições das famílias, já que a posição da família influencia, mas não determina a posição da criança. Além disso, "[...] não se pode realizar apenas uma análise em termos de posições sociais, é necessário considerar também a história do sujeito, a de sua construção e de suas transformações" (CHARLOT, 2005, p. 40). Olhar por esse lado é, de acordo com Charlot (2000, p. 30), "[...] prestar atenção também ao que as pessoas fazem, conseguem, têm e são [...]".

Nesse sentido, apresentamos no Quadro 3 algumas narrativas dos/as entrevistados/as sobre a importância do estudar/aprender.

\section{Quadro 3: A importância de estudar/aprender}

\section{\begin{tabular}{|l|l|}
\hline Professor/a & Narrativas \\
\hline
\end{tabular}}




\begin{tabular}{|c|c|}
\hline Araujo & $\begin{array}{l}\text { "[...] eu gostava demais, como até hoje eu gosto de estudar [...]estudo para } \\
\text { mim sempre foi muito importante, a base para qualquer coisa na vida". } \\
\text { "O meu primeiro contato com a escola eu tinha seis anos de idade. Então } \\
\text { era num ambiente muito legal, muitas crianças de muitas idades, eu acho } \\
\text { que não tinha separação de série. [...] nós tínhamos o momento da } \\
\text { higienização até dental, nós tínhamos uma escova, eu me lembro até hoje, } \\
\text { eu tinha uma escovinha vermelha com o meu nome. Eu aprendi a } \\
\text { identificar meu nome pela minha escova". } \\
\text { "[...] Na verdade eu posso dizer assim, eu cresci dentro de uma escola, } \\
\text { minha mãe era merendeira dessa escola onde eu fiz a primeira etapa do } \\
\text { fundamental. A minha mãe era merendeira e eu vivia lá dentro, os alunos } \\
\text { iam embora e eu voltava para ajudar a minha mãe por cima das mesas } \\
\text { brincando, escrevendo na lousa. } \\
\text { "Nunca me vi parando no meio do caminho, nunca [...] eu nunca pensei } \\
\text { em parar de estudar, é tanto que fiz o ensino médio duas vezes". }\end{array}$ \\
\hline Barbosa & $\begin{array}{l}\text { "Eu lembro, do meu primeiro ano de escola, eu fui contemplado, eu ainda } \\
\text { me lembro, um livro que a professora me deu, um livrinho [...] considerado o } \\
\text { melhor aluno da sala". } \\
\text { "[...] toda a minha vida eu tive que trabalhar desde cedo, estudar e } \\
\text { comecei a trabalhar muito jovem, assim desde já no primeiro ano do ensino } \\
\text { médio". }\end{array}$ \\
\hline Oliveira & $\begin{array}{l}\text { "[...]desde criança eu sempre gostei de ler, li muito, eu lia muito e isso me } \\
\text { dava expectativa, uma esperança de uma vida melhor, por isso nunca } \\
\text { parei de estudar". } \\
\text { [...] eu lia muito livro de literatura. Então os meus momentos de diversão } \\
\text { eram nos livros de literatura. É, meu primeiro livro de literatura brasileira, eu li } \\
\text { na oitava série é, o Guarani, de José de Alencar, onde foi a porta aberta } \\
\text { para o mundo da literatura brasileira". } \\
\text { "Eu era tão usuária da biblioteca que eu já nem assinava o livro de } \\
\text { empréstimo, eu só pegava o livro, mostrava para a atendente e saía. E ela } \\
\text { falava: - sete dias no máximo. Com três dias eu devolvia o livro, já pegava } \\
\text { outro. Então em média eu lia dois, três livros em sete dias [...]". } \\
\text { "Se estudava e muitas vezes nem sabia onde esse caminho ia dar, não ée } \\
\text { Mas eu estudava para aprender". }\end{array}$ \\
\hline Souza & $\begin{array}{l}\text { "[...]estudo para a gente sempre foi muito sério [...] Eu sempre gostei, na } \\
\text { verdade eu sempre gostei de ir para a escola [...] eu não gostava de perder } \\
\text { nada [...] Então eu sempre tive consciência de que o meio de eu mudar de } \\
\text { vida era estudando, porque senão ia ficar realmente difícil". } \\
\text { "[...] eu sempre gostei muito de ler e de observar as pessoas, e de leitura e } \\
\text { de poesia". }\end{array}$ \\
\hline
\end{tabular}

Fonte: Dados da pesquisa (2017).

Como foi colocado no Quadro 3, as professoras Araujo e Oliveira demonstraram ao longo de sua história de vida uma relação de valorização da escola. A professora Oliveira aprendeu a ler e a escrever aos cinco anos. Já a professora Araujo exemplificou como conseguiu identificar as primeiras letras quando aprendeu seu nome fazendo relações com a escovação dos dentes. O professor Souza contou com o auxílio de parentes que eram 
professores e o ajudaram nesse caminho. O professor Barbosa chegou a ser reprovado devido a rigidez do ensino ofertado nos tempos de escola, quando criança.

Nesse sentido, aprender alguma coisa é passar da "não-posse" para a "posse", pode ser também o domínio/apropriação de uma atividade, ou dominar uma relação; significa interiorizar algo, torná-lo seu. A relação com o saber implica dimensões epistêmicas e identitárias, porque "aprender faz sentido por referência à história do sujeito, às suas expectativas, às suas referências, à sua concepção de vida, às suas relações com os outros, à imagem que tem de si e à que quer dar de si aos outros" (CHARLOT, 2000, p. 72).

Dentre os/as professores/as entrevistados/as, Barbosa foi o único que teve em seu percurso de formação a experiência de fazer o exame de admissão, que era necessário para dar continuidade a escolarização. Alguns elementos faz-nos entender como os percursos de formação são singulares, ou seja, cada sujeito é "um ser singular, exemplar único da espécie humana, que tem uma história, interpreta o mundo, dá um sentido a esse mundo, à posição que ocupa nele, às suas relações com os outros, à sua própria história, à sua singularidade" (CHARLOT 2000, p. 34).

Para entender a relação com o saber é preciso conhecer e compreender as figuras do aprender. São elas:

[...] Objetos-saberes, isto é, objetos aos quais um saber está incorporado: livros, monumentos e obras de arte, programas de televisão "culturais"; objetos cujo uso deve ser aprendido, desde os mais familiares (escova de dentes, cordões do sapato...) até os mais elaborados (máquina fotográfica, computador...); atividades a serem dominadas, de estatuto variado: ler, nadar, desmontar um motor; dispositivos relacionais nos quais há que entrar e formas relacionais das quais se devem apropriar, quer se trate de agradecer, quer de iniciar uma relação amorosa (CHARLOT, 2000, p. 66).

Desse modo, quando o sujeito aprende que pode construir um saber específico, como a compreensão de um saber intelectual (a matemática, a história da arte, a gramática), pode também dominar um objeto ou uma 
atividade (como ler, caminhar, amarrar os sapatos, etc.) e pode aprender formas de se relacionar com os outros e com o mundo (cumprimentar as pessoas, namorar, etc.).

Os/as professores/as estavam aprendendo a dominar atividades, seja de leitura e escrita e, como vimos, esses domínios se caracterizam em figuras do aprender (CHARLOT, 2000). Dominar a atividade da leitura possibilitou Oliveira conhecer e ler os livros de literatura, fez com que ela pudesse se apropriar de um saber: os conteúdos dos livros de literatura. Barbosa foi presenteado com um livro pela professora como melhor aluno da sala. Os livros se caracterizam como objetos-saberes, nos quais o saber é depositado, onde o saber pode ser acessado (CHARLOT, 2000).

A prática da leitura fez com que Oliveira tivesse uma relação singular com a biblioteca e as pessoas que lá trabalhavam. Notamos que o domínio da leitura, atividade que Oliveira aprendeu em casa através dos gibis, foi aprimorado na escola, proporcionando-lhe a construção de outras relações, em outros espaços como, por exemplo, a biblioteca municipal da cidade de Araguaína-TO.

A relação com a escola também aparece como encanto e desejo. Quando se mudou para a cidade de Araguaína-TO, para trabalhar na casa da patroa, Oliveira relata que ao ver as pessoas indo à escola, sentiu desejo de fazer outro ensino médio. Oliveira significa a escolarização em sua trajetória de vida como "libertação", levada pelo "desejo" de estudar (CHARLOT, 2000, p. 57) que encontra sentido na possibilidade de mudança de vida. Desejo que a professora Araujo também demonstra quando objetiva concluir a escolarização e ingressar na universidade, o que era um "sonho". Tal dedicação possibilitou que fossem selecionadas no vestibular para Geografia e Letras na Universidade Federal do Tocantins (UFT), e no concurso do estado do Tocantins para professora efetiva.

Além do domínio das atividades de leitura e escrita, os/as entrevistados/as também destacaram em suas narrativas outra figura do aprender, a aquisição de alguns saberes específicos que se apropriaram ao longo de sua formação. 
Assim, no âmbito das figuras do aprender, os/as professores/as destacam objetos-saberes, como os livros; saberes específicos, como a literatura; também formas de se relacionar com professores, alunos, com a sala de aula, com a universidade e com eles mesmos. Como vimos, para Charlot (2000), os saberes são sempre elaborados na relação com outras pessoas e aprender significa a apropriação por parte dos sujeitos de um saber que está depositado em objetos (livros), locais (escola, universidade, sala de aula) e pessoas (alunos, professores).

\section{TIPOS DE RELAÇÃO COM O SABER E COM A ESCOLA}

No caminho de entender a importância da escola, enquanto lugar de formação, destacamos as ideias do geógrafo Tuan (2013), que faz uma discussão sobre os conceitos de espaço e lugar a partir da perspectiva da experiência. As ideias desse autor vêm auxiliar-nos a pensar a escola para além de uma instituição estatal de formação, mas também, como um lugar dotado de significados e pelo qual os professores estabelecem uma forte relação de afetividade.

Tuan (2013) se preocupa em mostrar como o espaço se torna lugar a partir da experiência dos sujeitos. Isso nos interessou para compreender as relações com a escola, identificadas nas narrativas dos professores, ao passarem de espaços para lugares de formação, pelos vínculos construídos, pelas pessoas marcantes, etc., pois, "os lugares são centros aos quais atribuímos valor" (TUAN, 2013, p. 12), e isso ocorre através das diversas experiências humanas com esses lugares.

Como vimos, a família de Araujo "sempre priorizou o estudo", assim como as famílias dos/as outros/as professores/as, mas há uma peculiaridade na sua história de vida. A escola primária mostra-se como uma escola marcante, por ter sido a primeira escola onde estudou e que depois retornou como professora, mas também, porque essa escola sempre esteve localizada próxima à sua casa. Quando criança, já ia com sua mãe que trabalhou na escola como merendeira, isto é, antes mesmo de iniciar a escolarização já conhecia, de certa forma a escola e as salas de aula. 
As recordações de Araujo sobre a Escola Municipal Gentil Ferreira Brito se estendem na sua atuação como professora, ao narrar que podia fazer coisas e entrar em locais como professora que não tinha acesso como estudante. As memórias se remetem a estrutura física, mas também às experiências vividas. São experiências formadoras para os sujeitos, nas quais estão presentes vários elementos como processos, temporalidades, aprendizagens, conhecimentos, etc. Para Josso (2004, p. 48),

[...] Falar das próprias experiências formadoras é, pois, de certa maneira, contar a si mesmo a própria história, as suas qualidades pessoais e socioculturais, o valor que se atribui ao que é 'vivido' na continuidade temporal do nosso ser psicossomático. Contudo, é também um modo de dizermos que, neste continuum temporal, algumas vivências têm uma intensidade particular que se impõe à nossa consciência e delas extrairemos as informações úteis às nossas transações conosco próprios e/ou com o nosso ambiente humano e natural.

Souza também teve a experiência de estudar na Escola Municipal Jonatas Pontes Arrais e retornar como professor. Ele sempre gostou da instituição porque "era uma escola diferenciada", onde "mais conseguiu aprender". Afirma ter uma "paixão" por essa escola, "para mim é a minha escola, pela maneira que eu aprendi, de ter essa questão sentimental, de ser a escola onde eu já [...] havia estudado. Então tem toda uma diferença". Percebemos que as experiências vividas pelo professor nessa escola, possibilitou que ele desenvolvesse uma relação de afetividade, de valorização e de reconhecimento.

Pensamos que as experiências que Araujo e Souza viveram nas escolas que estudaram e retornaram como professores serviram e servem de referência para a relação com as outras escolas, pois foi o primeiro exemplo de escola que tiveram contato. São as recordações-referências (JOSSO, 2004), que também podem ser chamadas de experiências formadoras. Em outras palavras, vivenciaram como estudantes e como professores experiências que fizeram sentido para eles e que foram importantes para sua formação, elas se tornaram referência no contexto de suas histórias de vida. Segundo Tuan (2013, p. 14): 
[...] Na experiência, o significado de espaço frequentemente se funde com o de lugar. 'Espaço é mais abstrato que lugar'. O que começa como espaço indiferenciado transforma-se em lugar à medida que o conhecemos melhor e o dotamos de valor. Os arquitetos falam sobre as qualidades espaciais do lugar, podem igualmente falar das qualidades locacionais do espaço. As ideias de 'espaço' e 'lugar' não podem ser definidas uma sem a outra. A partir da segurança e estabilidade do lugar estamos cientes da amplidão, da liberdade e da ameaça do espaço, e vice-versa. Além disso se pensamos no espaço como algo que permite movimento, então o lugar é pausa; cada pausa no movimento torna possível que localização se transforme em lugar.

Passar do espaço ao lugar pressupõe um processo, do qual se fazem presentes vários elementos e, nas narrativas docentes percebemos que a relação com a escola se fortaleceu ao longo dos anos; o espaço que era desconhecido foi se tornando um lugar de formação. A escola se torna então um núcleo de valor, onde por intermédio da experiência se passa de espaço a lugar (TUAN, 2013), o que pode ser percebido através das narrativas dos professores que evidenciam esse processo de criação de intimidade com as escolas onde estudaram e com os saberes construídos.

O saber, para Charlot (2000), é atividade e relação, uma relação do sujeito com o seu mundo, com as pessoas, com os objetos. O que nos faz pensar na cultura como um elemento importante para a compreensão das diversas relações que o sujeito estabelece com o mundo, porque,

\begin{abstract}
A cultura não é somente um conjunto de saberes, de práticas e de comportamentos, ela adquire uma forma de individualidade: 0 artesão, o 'operário da indústria', o médico da zona rural, o professor das séries iniciais da Terceira República etc. Ela é também uma relação de sentido com o mundo: é culto aquele para quem o mundo não é somente lugar em que atuar, mas um universo de sentido. A cultura, enfim, é o processo pelo qual um indivíduo se cultiva, tornando-se portador e gerador de sentido (CHARLOT, 2005, p. 95).
\end{abstract}

Desse modo, nos interessou evidenciar as trajetórias de escolarização de cada professor entrevistado, compreendendo-os como seres singulares e que atribuem sentidos ao se relacionar com a escola, com os saberes, com os professores e com os diversos lugares de formação. 
Nesse processo, alguns tipos e lógicas de relação com o saber se apresentaram nas narrativas, e os/as sistematizamos nos Quadros 4 e 5 para melhor compreensão.

\section{Quadro 4: Tipo de saber: sentidos de ir à escola, sentidos de aprender}

\begin{tabular}{|l|l|}
\hline Professor/a & Narrativas \\
\hline Araujo & $\begin{array}{l}\text { "é um meio de libertação" } \\
\text { "a educação é um caminho para uma sociedade melhor" } \\
\text { "era prazeroso estudar na minha época" } \\
\text { "estudo para mim sempre foi muito importante, a base pra qualquer } \\
\text { "o estudo, ele faz com que a pessoa rompa barreiras e alcance muitos } \\
\text { objetivos" }\end{array}$ \\
\hline Barbosa & $\begin{array}{l}\text { "eu sempre gostei de estudar" } \\
\text { "essim" querendo aprender mais, o que a gente sabe é muito pouco } \\
\text { "conhecimento também é importante, até mais que o título" } \\
\text { "meu patrimônio é mais intelectual do que material" }\end{array}$ \\
\hline "a educação é o incrivel a transformação que ela causa na vida das \\
$\begin{array}{l}\text { pessoas" } \\
\text { "era como se fosse uma válvula de escape" } \\
\text { "foi uma oportunidade de ter saído e não ter continuado o ciclo de } \\
\text { família" } \\
\text { "eu vejo a educação como um meio de mudar, superar, crescer" } \\
\text { "estudava, eu sempre estudei muito, não fingia que estudava" }\end{array}$ \\
$\begin{array}{l}\text { "ter um futuro" } \\
\text { "estudo para a gente sempre foi muito sério" } \\
\text { "o meio de eu mudar de vida era estudando" } \\
\text { "eu sempre tive essa convicção de que minha vida só podia melhorar } \\
\text { se eu estudasse" } \\
\text { "é o único meio de você mudar a sua realidade" }\end{array}$
\end{tabular}

Fonte: Dados da pesquisa (2017).

Para Charlot (2011, p. 1), a questão da relação com o saber envolve responder as seguintes questões: "Para um aluno dos meios populares, qual é o sentido de ir à escola? Qual é o sentido de aprender, quer na escola, quer fora da escola?". Essas questões também podem ser direcionadas aos professores: "qual é o sentido de ir todo dia para ensinar na escola? Por que a cada dia vocês vão à escola? [...] Qual o sentido de ensinar crianças para vocês?".

Dialogando com essas questões, observando o Quadro 4, e os trechos das narrativas destacados até aqui, percebemos que a escola para os/as professores/as se apresenta em termos de futuro. Qual o sentido de ir à 
escola para eles, como estudantes? Ter a oportunidade de mudança de vida, não passar pelas mesmas dificuldades pelas quais os pais passaram. lam à escola para aprender, porque para melhorar as condições de vida através da escola, era preciso além de estar lá, poder passar de ano, continuar os estudos e dessa forma ter um futuro melhor.

No Quadro 4, buscamos sintetizar os saberes narrados pelos/as professores/as como sentidos de ir à escola, sentidos de aprender, que também poderia ser relação com a escola, com o aprender, com a escolarização, etc., desdobrando-se em vários outros saberes narrados pelos/as professores/as. O objetivo desse Quadro foi trazer saberes que as professoras e professores elaboraram, sobretudo, com influência familiar, mas também de outros lugares, sobre o sentido de ir à escola, sobre a postura frente à educação escolar, sobre o que os mobilizava para dar continuidade aos estudos. São lógicas da relação com o saber que emergiram das histórias de vida e da formação dos/as entrevistados/as.

Charlot (2011) destaca como resultados de suas pesquisas quatro relações de estudantes com o saber, quatro processos fundamentais. $O$ primeiro: "o aluno que adora estudar! Ele começa a ler geralmente aos quatro anos, gosta de ler, gosta de aprender, não temos nenhum problema com ele. O aluno gosta tanto de aprender que nenhum método pedagógico impede-o de aprender" (p. 3). O segundo é o aluno que vive a escola como uma "conquista permanente". O terceiro é o aluno que vai para a escola para passar de ano, para ter um diploma, para ter um bom emprego. Na escola fazem o que a professora diz que tem que fazer e muitos não encontram o sentido ou o prazer de estudar, eles pensam que quem deve ser ativo no processo de ensino aprendizagem é somente o/a professor/a, "eles esperam que a palavra da professora entre diretamente na cabeça deles" (CHARLOT, 2011, p. 4). O último processo envolve os alunos que são "perdidos" na escola, que evadem da escola, "alunos que estiveram presentes fisicamente, mas que nunca entraram nas lógicas simbólicas da escola, que nunca entenderam do que se trata" (CHARLOT, 2011, p. 3). 
A partir das narrativas, pensamos que os/as entrevistados/as se inserem, sobretudo, na perspectiva da escola como uma conquista permanente, ao existir "uma vontade enorme de ser bem-sucedido", ao se mostrarem determinados, mesmo enfrentando dificuldades, enxergam a escola em termos de futuro. Cabe ressaltar que os estudantes pesquisados por Charlot (2011), como ainda se encontravam na situação de alunos não tinham ideia se seriam ou não bem-sucedidos na escola. Já os sujeitos desta pesquisa narram essas relações a partir do presente, como professores, de certa forma a escola foi fundamental para eles. Por isso, nos deparamos com narrativas que afirmam o gosto pela escola, pelos estudos e significam a escolarização como a única oportunidade que tinham para mudarem de vida.

Quadro 5: Tipo de saber: a escola como lugar do saber

\begin{tabular}{|l|l|}
\hline Professor/a & Narrativas \\
\hline Araujo & $\begin{array}{l}\text { "era um ambiente muito legal" } \\
\text { "eu nunca fui de ficar mudando de escola" } \\
\text { "no decorrer do tempo já ia me apaixonando pela nova escola" }\end{array}$ \\
\hline Barbosa & $\begin{array}{l}\text { "é o lugar do saber" } \\
\text { "eu acho que a escola devia também funcionar dessa forma, final de } \\
\text { semana tá aberta a comunidade" } \\
\text { "eu não tenho preferência por escola" }\end{array}$ \\
\hline Oliveira & $\begin{array}{l}\text { "passei a me sentir parte da escola" } \\
\text { "tu passa a se identificar, a se sentir parte da escola" }\end{array}$ \\
\hline "eu me sinto em casa" \\
\hline $\begin{array}{l}\text { "então hoje a escola continua sendo [...] o lugar da mudança, é o } \\
\text { lugar de você mudar a sua história, mudar o rumo da sua vida" } \\
\text { "a escola ainda é o lugar da transformação" }\end{array}$ \\
\hline
\end{tabular}

Fonte: Dados da pesquisa (2017).

Na escola não está presente apenas um tipo de figura do aprender, como os saberes específicos das diversas disciplinas, mas na escola também se aprende atividades como a leitura e a escrita, aprende a se relacionar com as pessoas, com professores/as e colegas. Charlot (2002, p. 24) destaca que, 
A questão do saber é central na escola. Não se deve esquecer que a escola é um lugar onde tem professores que estão tentando ensinar coisas para os alunos e os alunos estão tentando adquirir saberes. Aí está a definição fundamental da escola. Estou falando do saber num sentido geral, que inclui imaginação, exercício físico, estético e sonhos também. Mas a escola é um lugar de saber e isso é muito importante.

A escola apresentada pelos professores é um lugar acolhedor, onde se aprende coisas, onde se transforma vidas, onde se muda histórias. Uma escola que deve estar aberta à comunidade e pela qual os professores se apaixonam, que até se sentem em casa. Claro que estamos falando de muitas escolas, não apenas de uma. Os professores estudaram e trabalharam em várias escolas durante suas histórias de vida e construíram saberes sobre elas.

Outra questão que emergiu das narrativas, como podemos ver no Quadro 5, é a relação de pertencimento que as professoras e professores criam(ram) com as escolas. Até mesmo porque, seja como estudante ou como professor/a, a escola é o lugar ao qual mais dedicam tempo. As escolas são lugares onde se criam vínculos, laços, onde se sentem bem. Mas esses laços não são construídos de uma hora para a outra, para isso se requer tempo e experiências para que uma ou outra escola se torne importante.

A partir das narrativas dos/as professores/as percebemos que a escola pode ser entendida como um lugar de estudar, do saber, de formação, de relações com colegas e com professores. Para Tuan (2013), lugar pode ser onde guardamos nossas memórias, isto é, através da experiência, que os espaços se tornam lugares. A experiência pode ser entendida como

[...] um termo que abrange as diferentes maneiras por intermédio dos quais uma pessoa conhece e constrói a realidade. Essas maneiras variam desde os sentidos mais diretos e passivos como o olfato, paladar e tato, até a percepção visual, ativa e a maneira indireta de simbolização. [...] a experiência implica a capacidade de aprender a partir da própria vivência. [...] a experiência é constituída de sentimento e pensamento (TUAN, 2013, p. 17-19). 
Não só a escola se apresenta como espaço-lugar de sentimentos, de formação, a universidade também tem essa importância. Mas percebemos que na escola essa relação de afetividade é mais evidente. Para Tuan (2013, p. 17), a "permanência é um elemento importante na ideia de lugar"; "o espaço se transforma em lugar quando possui definição e significado" (p. 167). O lugar é o espaço com significados, o lugar é significado a partir da relação corpórea e simbólica do sujeito.

Quando o sujeito sai de uma escola para outra, por exemplo, ele chega a um espaço, no qual tem um distanciamento, que é a princípio indiferente e pelo qual não tem envolvimento. Com o tempo, a relação passa a ser de proximidade, de intimidade, de envolvimento. Observamos ao longo deste trabalho que todos os espaços e tempos da vida são de formação (BRAGANÇA, 2012a). O espaço familiar, escolar, universitário, da sala de aula são espaços de formação para as professoras e professores. As muitas experiências narradas pelos/as docentes ao longo das histórias de vida, nos possibilitam compreender que,

[...] A ampla delimitação de contextos e situações de vida, das mais diversas atividades, de encontros que marcam a vida - as pessoas significativas da família, os acontecimentos pessoais e sócio-históricos -, começam a desenhar os contornos da singularidade de um percurso de formação, e começa a evidenciar aprendizagens; momentos-charneira e desafios que os atravessam; valores ou valorizações que orientaram escolhas, bem como preocupações e temas recorrentes (JOSSO, 2004, p. 64).

Conhecer as histórias de vida dos professores e suas relações com o mundo, com as pessoas e consigo mesmo nos permitiu refletir

[...] sobre o sentido formativo da experiência narrativa das professoras, na vivência da pesquisa. Entretanto, é preciso também, aqui, referir que ouvir a história das professoras mobilizou um intenso movimento de reflexão e de formação na investigadora. Ao ouvir a história do outro, refletimos sobre nossa própria trajetória. Assim, a investigação-formação foi abrindo canais para uma aprendizagem partilhada, na tematização de percursos de vida (BRAGANÇA, 2012b, p. 588). 
Desse modo, Charlot (2005, p. 77) afirma que a "educação sempre supõe uma relação com o Outro" e esse "Outro" pode ser um conjunto de valores, de objetos, de práticas, mas também, outro ser humano. Segundo o autor, "o docente é, ao mesmo tempo (com suas características pessoais), um representante da instituição escolar (com direitos e deveres) e um adulto encarregado de transmitir o patrimônio humano às jovens gerações (o que é uma função antropológica)" (CHARLOT, 2005, p. 77). Para Charlot (2005, p. 77), a relação professor e estudante é uma relação de duas gerações, "a que entra na vida e a que traz um patrimônio 'já aí', estão envolvidos em uma "relação antropológica", em que um precisa do outro".

Nesse sentido, destacamos que entender o constituir-se professor/a implica pensar a formação ao longo da vida como centro das investigações, significa perceber os docentes como sujeitos históricos que, a partir das interações humanas vão se educando, se apropriando de saberes e se recriando, assim, a educação, a aprendizagem e a formação são processos que perpassam toda a nossa trajetória. Nesse contexto, as escolas se colocam como espaços-lugares em que esse movimento acontece de forma sistematizada. Ao nascer com a obrigação de aprender, é através da educação, que pode ocorrer em variados espaços, além da escola, que os professores ampliam sua visão de mundo.

A trajetória de cada professor/a traz aprendizagens oriundas tanto da vida pessoal, da formação escolar e acadêmica e da experiência profissional. Assim, entendemos que a partir das experiências de vida, cada professor/a estabelece uma relação pessoal e significativa com o saber, com a família, com a escola e com a sua formação como professor/a.

\section{CONSIDERAÇÕES FINAIS}

Os/as professores/as entrevistados/as se construíram como sujeitos na relação com outras pessoas, sobretudo da família, como o pai da professora Oliveira e o tio do professor Barbosa; e da escola, na figura dos professores. A relação com o saber e a escola foi elaborada, principalmente a partir de 
saberes construídos e compartilhados nesses lugares, desde objetos-saberes às figuras do aprender no âmbito mais geral.

As experiências familiares e escolares se apresentaram como formadoras e marcantes. Os valores e as crenças aprendidos/as com a família apareceram como orientadores ao longo da vida; e as experiências escolares, seja como alunos e alunas ou como professores e professoras, orientaram a constituição de saberes sobre a docência, bem como a compreensão do que é ser professor/a.

Os entrevistados narraram relações de valorização da escola, que é percebida como um ambiente agradável, no qual é possível aprender a ler e a escrever; e a construir relações. A escola como espaço-lugar de formação apareceu num movimento de estranheza (espaço) e de afetividade (lugar), que proporcionou libertação, transformação. As passagens pelas muitas escolas, como estudantes, que proporcionaram sucesso escolar, a formação universitária e a experiência como professores em atuação permitiram que compreendessem a escola como lugar de possibilidades.

A escola apresentou-se como uma conquista permanente, narrativa que persistiu nas falas dos/as entrevistados/as, até os dias de hoje como professores. Portanto, percebemos a valorização da educação pelas suas famílias, como única possibilidade de mudança de vida. Mesmo sem condições socioeconômicas, essas famílias fizeram o que estava ao seu alcance para que os filhos estudassem, e essa demanda foi abraçada pelos/as entrevistados/as que revelaram os sentidos e os significados da educação escolar, sobretudo, em termos de futuro.

\section{REFERÊNCIAS}

ALBERTI, V. Histórias dentro da História. In: BINSKY, C. B. (Org.). Fontes

Históricas. 2 ed. São Paulo: Contexto, 2006, p. 156-202.

BRAGANÇA, I. F. de S. Histórias de vida e formação de professores: diálogos entre Brasil e Portugal. Rio de Janeiro: EdUERJ, 2012a. 
BRAGANÇA, I. F. de S. A formação como "tessitura da intriga": diálogos entre Brasil e Portugal. Revista Brasileira de Estudos Pedagógicos. Brasília, v. 93, n. 235, p. 579-593, set./dez. 2012b.

CHARLOT, B. Da relação com o saber: elementos para uma teoria. Tradução Bruno Magne. Porto Alegre: Artmed, 2000.

\section{CHARLOT, B. Relação com o saber, Formação dos Professores e}

Globalização. Porto Alegre: Artmed, 2005.

CHARLOT, B. Relação com a escola e o saber nos bairros populares.

Perspectiva. Florianópolis, v. 20, n. Especial, p. 17-34, jul./dez. 2002.

CHARLOT, B. Relação com o saber e com a escola entre estudantes de periferia. Cad. Pesquisa, São Paulo, n. 97, p. 47-63, maio 1996.

CHARLOT, B. A pedagogia ativa é uma conquista da professora com os alunos. In: AZEVEDO, J.; DIAS, R. (Orgs.). Educação e diálogo - Encontros com educadores em Várzea Paulista. Jaboticabal (SP), Funep, 201 1. p. 1-6.

JOSSO, M.-C. Experiências de vida e formação. Tradução José Cláudino e Júlia Ferreira. São Paulo: Cortez, 2004.

MEIHY, J. C. S. B.; HOLANDA, F. História Oral: como fazer, como pensar. 2 ed. São Paulo: Contexto, 2013.

PORTELLI, A. História oral como arte da escuta. Tradução Ricardo Santhiago. São Paulo: Letra e Voz, 2016.

THOMPSON, P. A voz do passado: História Oral. Tradução Lólio Lourenço de Oliveira: Rio de Janeiro: Paz e Terra,1992.

THOMPSON, P. Histórias de vida como patrimônio da humanidade. In: História falada: memória, rede e mudança social. Coordenadores Karen Worcman e Jesus Vasquez Pereira. São Paulo: SESC SP: Museu da Pessoa: Imprensa Oficial do Estado de São Paulo, 2006. p. 17-43.

TUAN, Yi-fu. Espaço e lugar: a perspectiva da experiência. Tradução Lívia de Oliveira. Londrina: Eduel, 2013.

\section{Fontes primárias}

ARAUJO, Edileuza Batista de. [37 anos]. [agosto, 2016]. Entrevistadora: Bruna da Silva Cardoso. Araguaína, agosto de 2016.

BARBOSA, José Humberto Gomes. [50 anos]. [setembro, 2016]. Entrevistadora: Bruna da Silva Cardoso. Araguaína, setembro, 2016. 
OLIVEIRA, Izarete da S. [40 anos]. [julho, 2016]. Entrevistadora: Bruna da Silva Cardoso. Araguaína, julho, 2016.

SOUZA, Ronaldo da Silva. [35 anos]. [agosto, 2016]. Entrevistadora: Bruna da Silva Cardoso. Araguaína, agosto, 2016.

Recebido em: 08 de junho de 2020 Aprovado em: 25 de setembro de 2020 Publicado em: 16 de outubro de 2020

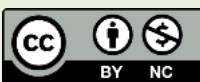

